\title{
A Call for
}

\section{SHEA}

\section{Board of Directors}

\section{Nominations}

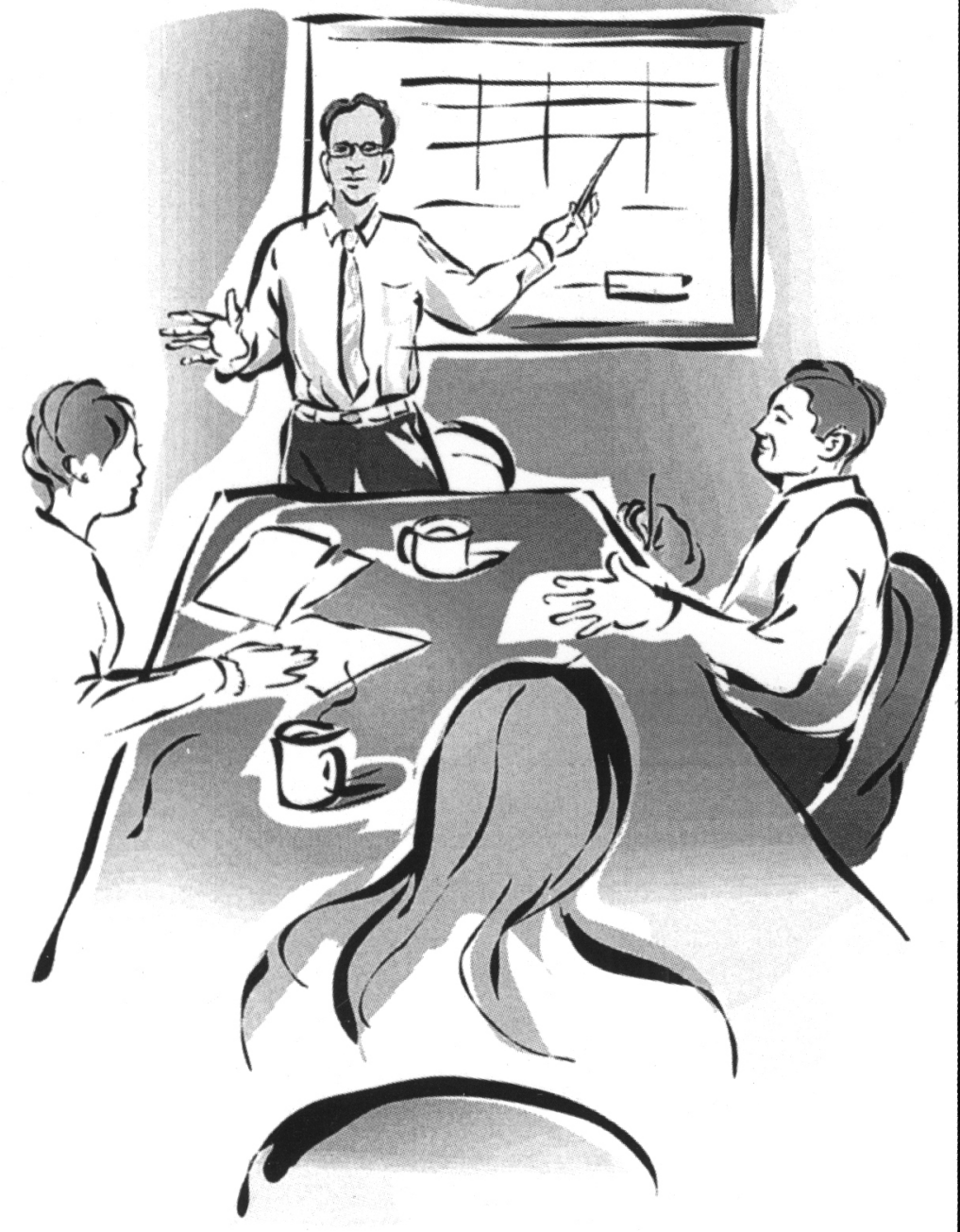

Candidates should have demonstrated commitment to SHEA and the field of healthcare epidemiology, and have experience in committee and volunteer work. If you are interested in serving or know of other members interested in serving, please obtain a Nominations form by visiting the SHEA website (www.shea-online.org), or write to SHEA Nominations Committee Chair, c/o SHEA Executive Office, 19 Mantua Road, Mt. Royal, NJ 08061. Nominations must be received by August 30, 2002 